\title{
ALGUMAS REFLEXÕES SOBRE A CIDADANIA CLÁSSICA E A PARTICIPAÇÃo DAS MULHERES NA POLÍTICA BRASILEIRA
}

\author{
Camyla Galeão de Azevedo ${ }^{1}$ \\ Ana Elizabeth Neirão Reymão ${ }^{2}$ \\ Suzy Elizabeth Cavalcante Koury ${ }^{3}$
}

\section{Resumo:}

O artigo discute a relação entre o conceito de cidadania clássica e a participação das mulheres na política brasileira. Apresenta-se o conceito clássico de cidadania, uma discussão sobre as noções de público e privado, de polis e oikos. A pesquisa é exploratória, de abordagem qualitativa, trazendo dados sobre a participação das mulheres na política brasileira que são analisados como evidências das implicações dessa noção clássica, que imputa papéis estereotipados para os gêneros e impõe obstáculos à participação das mulheres na esfera pública, desencadeando a baixa participação feminina na política formal no país.

Palavras-chave: cidadania clássica; público; privado; mulher; política.

\section{SOME REFLECTIONS ON CLASSICAL CITIZENSHIP AND WOMEN'S PARTICIPATION IN BRAZILIAN POLITICS}

\begin{abstract}
The paper discusses the relationship between the concept of classic citizenship and the participation of women in Brazilian politics. It is presented the classic concept of citizenship, the notions of public and private, polis and oikos. The research is exploratory, with a qualitative approach, bringing data about the participation of women in Brazil that are analyzed as evidence of the implications of this classic notion, imputing stereotyped roles for genders and imposing obstacles to the participation of women in the public sphere, triggering low participation in formal politics in the country.
\end{abstract}

Keywords: classic citizenship; public; private; woman; politics.

\footnotetext{
${ }^{1}$ Mestre em Direito pelo Programa de Pós-Graduação em Direito, Políticas Públicas e Desenvolvimento do Centro Universitário do Pará (CESUPA). Pós-graduanda em Direito Civil na PUC Minas Gerais. Advogada. E-mail: camylagaleao@gmail.com

${ }^{2}$ Economista (UFPA), Doutora em Ciências Sociais (UnB), Mestre em Economia (UNICAMP). Professora do Programa de Pós-Graduação em Direito, Políticas Públicas e Desenvolvimento (PPGD) do CESUPA. Professora da Faculdade de Economia da UFPA. Líder do grupo de pesquisas CNPq MinAmazônia (Mineração e Desenvolvimento Regional na Amazônia). E-mail: bethrey@uol.com.br

${ }^{3}$ Doutora em Direito pela Faculdade de Direito da Universidade Federal de Minas Gerais (UFMG). Desembargadora do Trabalho. Ex-presidente do TRT da $8^{\text {a }}$ Região (2016-2018). Professora do Programa de PósGraduação em Direito, Políticas Públicas e Desenvolvimento do CESUPA. Líder do grupo de pesquisas CNPq "Emprego, Subemprego e Políticas Públicas na Amazônia".

E-mail: suzykoury@gmail.com
} 


\section{1- INTRODUÇÃO}

Esse artigo discute a relação entre o conceito de cidadania clássica e a participação das mulheres na política brasileira. O conceito clássico de cidadania, criado pelos atenienses e romanos, realiza uma separação entre a polis e a oikos, entre o espaço público e privado. O espaço privado era destinado às mulheres, às coisas e aos escravos. Eram elas que se preocupavam e organizavam o lar. O espaço público, por sua vez, era destinado aos homens, sendo eles vistos como "seres naturalmente políticos", um kata phusin zoon politikon, indivíduos que, por sua própria natureza, tenderiam a viver em política (ARISTÓTELES, 2009; POCOCK, 2013).

A cidadania concedia o poder ao cidadão de governar e, ao mesmo tempo, ser governado, sendo restrita a apenas um certo grupo de indivíduos: indivíduos homens adultos. Somente eles poderiam se envolver no mundo político. Entretanto, para exercer a sua cidadania, teriam que se emancipar do mundo das coisas, deixar a oikos para trás e se dedicar, de forma exclusiva, à política. As mulheres estavam envolvidas demais no mundo das coisas para serem consideradas cidadãs, expressa essa noção.

No Brasil, um dado que chama atenção é que as mulheres se fazem bem menos presentes na política formal, preenchendo apenas 21,3\% das cadeiras parlamentares nacionais (MIGUEL, 2014). Em 2015, o país comprometeu-se a alcançar os Objetivos do Desenvolvimento Sustentável (ODS), propostos pela Organização das Nações Unidas (ONU) durante a Cúpula das Nações Unidas para o Desenvolvimento Sustentável, realizada em Nova Iorque. Metas globais foram fixadas para diversos temas considerados fundamentais para o desenvolvimento, tendo a Cúpula criado a Agenda 2030 e definido 17 ODS para assegurar direitos humanos, eliminar a pobreza e a fome, reduzir as desigualdades, construir sociedades justas e inclusivas, empoderar mulheres e meninas, bem como assegurar a proteção ao planeta e seus recursos naturais (PNUD, 2016).

Dessa forma, o ODS 5 foi definido como "Alcançar a igualdade de gênero e empoderar todas as mulheres e meninas", tendo o objetivo 5.5 estabelecido "Garantir a participação plena e efetiva das mulheres e a igualdade de oportunidades para a liderança em todos os níveis de tomada de decisão na vida política, econômica e pública” (PNUD, 2016).

Nesse contexto, questiona-se: que associações podem ser feitas entre a separação do âmbito público e privado, a polis e a oikos, e o conceito clássico de cidadania, que persiste por 
mais de dois mil anos? Esse é o problema de pesquisa do artigo preocupado com as implicações de, mesmo com as diversas conquistas realizadas pelo movimento feminista, as mulheres ainda sofrerem com a influência do poder patriarcal e das noções associadas ao conceito de cidadania clássica, impondo as desigualdades entre os gêneros e afastando o país do cumprimento do ODS 5.

A pesquisa aqui apresentada é, quanto aos objetivos, exploratória, visando proporcionar maior familiaridade com o problema investigado, explicitá-lo e construir hipóteses sobre a relação entre o conceito de cidadania clássica, a separação entre a polis e a oikos, a noção de espaço público e privado e a participação das mulheres na política brasileira. A abordagem é, predominantemente, qualitativa e, como procedimentos, usou-se o levantamento bibliográfico e documental, especialmente os estudos e dados do Tribunal Superior Eleitoral.

Após essa introdução, o texto apresenta o conceito clássico de cidadania, na teoria de Aristóteles. A seção 3 discute o público e o privado, a polis e a oikos. A participação das mulheres na política (formal) brasileira é tema da seção 4. Por fim, apresentam-se as implicações do conceito clássico de cidadania na participação das mulheres na política brasileira, bem como as considerações finais do estudo.

\section{2- O CONCEITO CLÁSSICO DE CIDADANIA}

O conceito clássico de cidadania clássica tem duplo sentido. O primeiro deles é interligado a um tipo de autoridade, que decorre de se ter expressado um ideal, de forma durável e canônica. Entretanto, nos referimos ao conceito clássico de cidadania interligado ao segundo sentido, referindo-se sempre às civilizações antigas do Mediterrâneo, em especial, à Atenas dos séculos V e IV a.C e à Roma, entre o século III a.C e o século I d.C.

Como mostra Pocock (2013), foram os atenienses e os romanos que criaram o ideal de cidadania, tal como conhecemos, e isso os torna clássicos. Esse é um dos valores enraizados em nossa civilização e à nossa tradição.

Aristóteles (2009) destaca que existem várias formas de governo e, em decorrência, diversas formas de cidadania. $\mathrm{O}$ cidadão não é o mesmo em todas as formas de governo. $\mathrm{O}$ conceito de cidadania clássica a que nos referimos é relacionado à democracia, principalmente porque é esse modelo de governo que se adapta à definição clássica de cidadania.

Ao nos referirmos a essa definição, deparamo-nos com o conceito de cidadão, chamado de polities, em grego, ou civis, em latim. O cidadão clássico é definido como um membro da 
polis ateniense ou da res publica romana. Por polis, entende-se uma pequena cidade que abrigava os bárbaros e se apresentava como uma forma de associação humana que alegadamente pertenciam em exclusivo a estes antigos povos mediterrâneos e foi por eles transmitidas à Europa e ao Ocidente. A comunidade de cidadãos é aquela em que o discurso toma o lugar do sangue e os atos de decisão tomam o lugar dos atos de vingança. Na polis ou na res publica romana, há uma maior organização da sociedade, regida então por um governo que governa e é, ao mesmo tempo, governado (POCOCK, 2013).

O conceito de cidadania e cidadão clássico pertence ao filósofo Aristóteles, na obra $A$ Política (2009), para quem cidadão clássico é aquele que governa, mas é, ao mesmo tempo, governado. Esse cidadão Aristotélico é investido de um certo poder e do momento que ele tenha um poder na mão, passa a ser cidadão.

No conceito clássico de cidadania, é melhor governar animais que coisas, mulheres que escravos, outros cidadãos (homens) do que mulheres, escravos e coisas que fazem parte do ambiente doméstico e familiar. O que faz com que o cidadão se constitua a mais alta ordem das coisas é a sua capacidade de governar, de ser um cidadão político, e isso provoca que governar sobre um nosso igual só é possível quando o nosso igual governa sobre nós. Ou seja, o cidadão governa e é governado apenas entre seus iguais, lembra Pocock (2013). Para governar e ser governado, os cidadãos associam-se entre si para realizar a tomada de decisões, devendo cada cidadão respeitar a autoridade dos demais, uma vez que todos igualmente governam e são governados, e quando todos se associam na obediência às decisões que eles próprios tomaram.

A cidadania clássica pregava a igualdade entre os cidadãos, porém a igualdade e a cidadania eram restritas para apenas algumas pessoas da polis ou da res publica romana. A igualdade é permitida e restrita apenas para os homens, pois "o Estado significa uma associação de homens que possuem o meio de suprir a sua existência" (ARISTÓTELES, 2009, p. 41).

Assim, as mulheres não eram consideradas cidadãs, vez que para ser cidadão e ter igualdade, era necessário o indivíduo ser do sexo masculino, mas de ascendência conhecida, patriarca, guerreiro e dono do trabalho de outrem (escravos) (POCOCK, 2013). Os requisitos relacionados à raça, classe e gênero eram condições para um indivíduo ser um cidadão e para que pudesse governar e ser governado. Portanto, para Aristóteles, os requisitos não pertencem a qualquer um.

Pocock (2013) mostra que esses requisitos sobreviveram ao próprio ideal de cidadania, tal como o filósofo exprimiu, persistindo na cultura ocidental por mais de dois mil anos. Até 
hoje, não nos livramos totalmente desses requisitos. Entretanto, diversas teorias, como a feminista, atacam esses ideais que ainda persistem. Por persistirem até a atualidade, questionase se esses pré-requisitos são acessórios ao próprio ideal de cidadania ou se são, efetivamente, essenciais.

O conceito clássico de cidadania, a partir da teoria Aristotélica, necessita de uma rigorosa separação entre o público e o privado, entre a polis e a oikos, entre pessoas e ações das coisas, como discute a seção a seguir.

\section{3- O PÚBLICO E O PRIVADO, A POLIS E A OIKOS}

Em Aristóteles (2009), a casa é espaço das mulheres e dos escravos. A política, por sua vez, é espaço exclusivamente para cidadãos homens adultos. Para ter o estatuto de cidadão, o indivíduo deve ser o chefe, o patriarca de uma casa de família, ou da oikos. O trabalho das mulheres e dos escravos satisfaz as necessidades básicas do cidadão e concede tempo livre para se dedicar exclusivamente em relações políticas com os outros cidadãos, os seus iguais.

Para Aristóteles, os homens adultos nascem naturalmente com o ímpeto político, mas são absolutamente estranhos aos cuidados domésticos:

É absurdo estabelecer uma comparação com os animais para afirmar que as mulheres devem exercer as mesmas funções que os homens, os quais são absolutamente estranhos aos cuidados domésticos. Também é perigoso constituir as magistraturas como faz Sócrates: ele as confia sempre às mesmas pessoas (ARISTÓTELES, 2009, p. 49).

Para exercer a sua cidadania e se envolver nas relações políticas, o cidadão tem que deixar a casa completamente para trás, vez que a casa não era lugar de trabalho dos homens, sendo sustentada sempre pelo trabalho de seus escravos e mulheres. Eram as mulheres que realizavam as tarefas domésticas, a organização básica do lar e a organização e gerenciamento do trabalho dos escravos.

Os cidadãos apenas se preocupavam com a oikos, mas não estavam no centro de suas atenções e prioridades. Os cidadãos jamais discutiam entre si assuntos relacionados à oikos, pois, somente "no caso de as coisas terem ficado muito mal é que seria necessário, para eles, tomar decisões, na assembleia concebida para assegurar o domínio patriarcal sobre o lar e seu funcionamento" (POCOCK, 2013, p. 226). O que discutem e decidem na assembleia são assuntos propriamente relacionados à polis e não ao oikos. Decidiam assuntos relacionados a 
guerra ou ao comércio da cidade com outras cidades, assuntos relacionados a autoridade ou virtude e assuntos que diziam respeito a relação dos cidadãos entre si.

Para Aristóteles (2009), a política é um bem em si mesmo e não uma condição prévia para o bem comum. Ela é o próprio bem comum. Nesse sentido, o que conta é a própria liberdade para participar de decisões políticas e não o conteúdo tomado nas decisões. A política possui a sua própria virtude. A cidadania, portanto, não é somente um meio para ser feliz, mas sim o próprio modo de ser feliz. O cidadão era feliz e praticava o bem unicamente por ser cidadão, independentemente do conteúdo dos seus atos e decisões tomadas.

O filósofo Aristóteles articulou a política de tal forma em que há uma rigorosa separação entre o privado e o público. Entre a oikos e a polis. O privado e o público não se misturam, a oikos e a polis são separadas. A política clássica, portanto, implica em uma fuga da oikos. Para exercer a sua liberdade de ser cidadão, o indivíduo deveria se emancipar totalmente de suas relações privadas. A casa, o espaço privado, era um meio em que se manejava instrumentos de ação para que o exercício da cidadania fosse exercido. Já a política era o fim em si mesmo. Dessa forma, segundo Pocock (2013), os escravos nunca escapariam do espaço privado, pois seu destino era ser instrumento, meio para que algo fosse produzido. As mulheres também nunca escapariam do lar, já que eram as quem mandavam e organizavam nos escravos e nas coisas pertinentes à oikos.

A polis é um fim em si mesmo. A Oikos é um instrumento para fornecer meios para que a política se concretize. A cidadania era negada das mulheres em razão de estarem envolvidas no mundo das coisas, nas relações materiais, produtivas, domésticas ou reprodutivas. Se alguém quiser tornar a cidadania disponível para essas pessoas, terá de escolher entre duas opções: emancipá-las dessas relações ou negar que elas são componentes negativos na definição de cidadania. Quem escolher a segunda opção estará à procura de uma nova definição de cidadania, radicalmente diferente da definição grega de Aristóteles, uma definição na qual o público e o privado não estejam rigorosamente separados e as barreiras que separam desapareciam totalmente. Isso porque para o conceito clássico de cidadania, é essencial que o conceito de público, polis, e privado, oikos, estejam completamente separados. A partir do momento em que se há a negação dessas barreiras, há, portanto, a criação de um novo conceito de cidadania para além daquela criada por Aristóteles em A Política (POCOCK, 2013).

A partir da teoria de Aristóteles (2009), infere-se que não é preciso elevar ao grau de cidadão aqueles dos quais a cidade necessita para existir. Aqueles que trabalham, efetivamente, 
como artesãos e escravos, não poderão ser cidadãos. A virtude política não pertence a todo cidadão, mas somente ao homem livre, ou seja, todos aqueles que não têm necessidade de trabalhar para viver. O cidadão livre e dotado de virtude deve dedicar-se, exclusivamente, ao mundo político (ARISTÓTELES, 2009, p. 88).

O ideal clássico de Aristóteles define a pessoa humana como um ser com cognição, ativo, moral, social e naturalmente político. Entretanto, segundo Pocock (2013), não parece que, para Aristóteles, um ser humano, dotado de todas essas capacidades, pudesse ser plenamente humano se não governasse a si próprio. Deveria governar a si mesmo, as coisas e aos demais, na casa de família e associar aos outros cidadãos, considerados seus iguais, a fim de governar e ser governado. Essa humanidade só era plenamente desenvolvida e acessível a um número muito reduzido de indivíduos, adultos, do sexo masculino. O cidadão adulto e homem era o único que possuía o desenvolvimento pleno de sua humanidade. O ser humano, plenamente desenvolvido era, para Aristóteles, um kata phusin zoon politikon, um indivíduo que, por sua própria natureza, tende a viver em política. Ao entrar para a vida política e exercer, efetivamente, a sua cidadania, o cidadão adquiriria o valor de ser humano.

Adquirir a condição de ser humano plenamente desenvolvido, portanto, dependia de sua emancipação do mundo das coisas e o consequente ingresso no mundo da política. Como mulheres e escravos não poderiam se emancipar da vida privada, da oikos, não poderiam adentrar para o mundo da política e, consequentemente, exercer a sua cidadania. Nessa seara, as mulheres, por não serem emancipadas do mundo das coisas, não poderiam ser consideradas seres humanos plenamente desenvolvidos. O pleno desenvolvimento era concedido apenas aos adultos do sexo masculino.

\section{4- A PARTICIPAÇÃO DAS MULHERES NA POLÍTICA BRASILEIRA}

A ideia de que as mulheres não poderiam se emancipar da vida privada, da oikos, não podendo adentrar para o mundo da política parece estar muito presente na sociedade brasileira. Apesar de os dados demográficos do país mostrarem que a população brasileira é, em sua maioria, de mulheres (51\%, segundo o Censo IBGE), o acesso ao mercado de trabalho, à educação formal, o valor dos rendimentos auferidos e a participação na política ainda são muito desfavoráveis. Essa tem sido uma longa jornada... 
Graças à atuação do movimento feminista, mesmo com as constantes lutas contra a força opressora do patriarcado, as mulheres têm conquistado muitos direitos. Biroli (2018) mostra que, no século XX, o acesso à educação e ao trabalho aumentou significativamente. Entre 1970 e o início do século seguinte, o percentual de mulheres economicamente ativas elevou-se de $18,5 \%$ para $55 \%$. Esse aumento pode se dar em razão do aumento da participação das mulheres no mercado de trabalho e, de uma certa forma, da própria emancipação do lar. Além de um maior acesso ao mercado de trabalho, verifica-se que houve um maior acesso à educação pelas mulheres. Atualmente, em média, as mulheres possuem mais tempo de educação formal do que os homens, passando a serem a maioria entre as pessoas matriculadas no ensino superior (BIROLI, 2018).

Apesar do crescente acesso ao mercado de trabalho e à educação formal, a diferença entre o rendimento médio das mulheres e dos homens permanece em torno de $25 \%$, significando que a profissionalização e a escolarização não garantiram acesso igualitário às diferentes ocupações (PINHEIRO, 2016). É na conjugação entre gênero, classe e raça que as posições relativas se estabelecem de fato. Segundo Biroli (2018), na pirâmide de renda e no acesso a postos de trabalho, à escolarização e à profissionalização, as mulheres brancas estão mais próximas aos padrões de oportunidades de homens brancos, apresentando vantagens aos homens negros. São as mulheres negras que integram a faixa mais pobre da população.

As hierarquias de gênero, classe e raça acabam por incidir na definição de quem terá acesso aos cargos e locais de poder. Entretanto, a divisão sexual do trabalho, imputando formas de construção do feminino, provoca que as mulheres tenham chances relativamente menores que os homens de ocupar posições na política e de dar expressão política, no debate público, as perspectivas, necessidades e interesses relacionados à sua posição social (BIROLI, 2018). Por possuírem menores credibilidades no espaço político, acabam por possuir menores possibilidades de influenciar decisões e a produção das normas que as afetam diretamente, havendo muitos obstáculos a ocupações e recursos:

A cidadania das mulheres é, portanto, comprometida pela divisão sexual do trabalho, que em suas formas correntes contribui para criar obstáculos ao acesso a ocupações e recursos, à participação política autônoma e, numa frente menos discutida neste capítulo, à autonomia decisória na vida doméstica e intima (BIROLI, 2018, p 24).

A luta pelo direito de voto e participação política já foi um ponto focal de conquista do movimento feminista. A priori, o acesso ao direito de voto provocaria o tão sonhado 
reconhecimento pelo Estado e pela sociedade de que as mulheres possuíam condições iguais aos homens de exercer sua vida cívica. Significou também que as mulheres possuem pautas e interesses próprios, que só podem ser representados e reconhecidos por outras mulheres na política, interesses esses que dizem respeito ao seu próprio gênero e que são irredutíveis à pessoa do seu marido (MIGUEL; BIROLI, 2014).

Predominava também a ideia de que a concessão de voto era via de acesso aos espaços de tomada de decisão, na qual as mulheres, conjuntamente com os homens, tornariam as decisões mais "permeáveis à presença das mulheres e mais sensíveis às suas demandas" (MIGUEL; BIROLI, 2014, p. 93). No entanto, após a concessão do sufrágio feminino, percebeu-se que a concessão de direito de voto às mulheres tornou perfeitamente compatível a convivência entre o direito de voto pelas mulheres e o sistema político formado por maioria masculina.

Apesar das conquistas ao longo dos anos, sob influência do poder patriarcal, do conceito clássico de cidadania e, consequentemente, da divisão sexual do trabalho, a baixa participação das mulheres na política se faz realidade no mundo inteiro. A pesquisa de Miguel (2014) mostra que as mulheres preenchem 21,3\% das cadeiras parlamentares nacionais. Segundo dados levantados pelo Instituto Brasileiro de Geografia e Estatística (IBGE, online, 2018), na pesquisa "Estatísticas de Gênero- indicadores sociais das mulheres no Brasil” (2018), o Brasil é o último país da América do Sul em presença feminina na Câmara dos Deputados. Elas ocupam apenas 54 das 513 cadeiras da Câmara.

Em nível mundial, dentre as 190 nações pesquisadas, o Brasil ocupa $152^{a}$ posição no ranking mundial de participação das mulheres na política (IBGE, online, 2018). O primeiro lugar no ranking é preenchido por Ruanda (61,3\% da política é composta por mulheres), seguido por Cuba (48,9\% composta por mulheres), Suécia (43,6\%) e Argentina (38,1\%). Em apenas 27 de 187 países as mulheres correspondem um terço ou mais de vagas de candidatos.

Nas eleições de 2010, conforme dados apresentados pelo Tribunal Superior EleitoralTSE, disputaram para deputados federais 4.904 candidatos, os quais apenas 945 destes $(19,06 \%)$ eram candidatura de mulheres, e eleitas apenas 45 (4,07\%) candidatas. Em contraposição, 3.969 (80,93\%) das candidaturas eram masculinas, tendo 468 candidatos sido eleitos (11,79\%). Em comparação, dos 513 candidatos eleitos ao cargo, 91,22\% das cadeiras foram preenchidas por homens e apenas $8,77 \%$ preenchidas por mulheres (LIMA, 2015). 
$\mathrm{Na}$ mesma eleição, dos 9 candidatos à vaga de presidência, apenas duas eram preenchidas por mulheres, na qual se elegeu a primeira presidente mulher do Brasil: Dilma Rousseff. Embora esta tenha sido eleita para a Presidência em 2010 e 2014, entre os 27 Estados que compõem a Federação Brasileira, apenas um elegeu uma mulher como governadora. Em 2016, somente 11,5\% dos municípios elegeram mulheres como prefeitas (BIROLI, 2018).

Nas eleições gerais de 2014, dos 12 candidatos à vaga da Presidência, apenas três eram mulheres. Na mesma eleição, a Presidente Dilma Rousseff foi reeleita. Quanto ao cargo de deputado federal, as mulheres ocuparam 51 vagas, as quais as parlamentares brancas ocupam $8 \%$ das cadeiras, as pardas $1,6 \%$ e as negras 0,6\% (CÂMARA DOS DEPUTADOS, online, 2014).

Nas eleições municipais de 2016, no Brasil, verificou-se 5.474 candidatos eleitos aos cargos de prefeito, sendo apenas 638 mulheres. No mesmo ano, dos 57.862 candidatos a vereador, apenas 7.812 candidatos eram mulheres (TSE, online, 2016). Das prefeitas eleitas, 454 eram mulheres brancas e 3.393 eram homens brancos, entre os quais apenas dez mulheres negras foram eleitas. Com relação ao cargo de vereador, dos 57.862 candidatos, 4.879 mulheres brancas foram eleitas, número bem inferior aos 28.187 homens brancos eleitos. Com relação às mulheres eleitas ao cargo de vereadora, apenas 329 mulheres negras foram eleitas em todo o Brasil (TSE, online, 2016).

Curioso destacar que, apesar da pouca representatividade direta na política nacional (cargos eletivos), as mulheres preenchem bem o eleitorado brasileiro, correspondendo, nas eleições de 2016, 52,9\% do total. Com relação ao gênero e nível de formação, havia 60,24\% era formado por mulheres com ensino superior completo contra $39,74 \%$ do eleitorado composto por homens com ensino superior completo (TSE, online, 2018).

Como mostram os dados apresentados, a participação das mulheres é significativamente menor que a participação masculina na política. Mesmo compondo a maior parte da população brasileira, estando presente no mercado de trabalho, bem como compondo o maior eleitorado com nível superior, as mulheres enfrentam grandes obstáculos a participação na política. Esses obstáculos surgem em decorrência a diversos fatores, como a divisão sexual do trabalho. Entretanto, um dos maiores fatores históricos para a própria segregação das mulheres do espaço de convivência política, relaciona-se ao conceito clássico de cidadania, que permeia a sociedade por mais de dois mil anos ao longo da história, produzindo reflexos de forma direta na participação política das mulheres atualmente. 


\section{5- IMPLICAÇÕES DO CONCEITO CLÁSSICO DE CIDADANIA NA PARTICIPAÇÃO DAS MULHERES NA POLÍTICA BRASILEIRA}

Frente à baixa participação na política formal, como mostrado na seção anterior, cumpre analisar de que forma o conceito de cidadania clássica, impondo a separação entre o público e o privado, produz consequências para inserção e participação política dessas mulheres atualmente.

A cidadania clássica, criada pelos Atenienses e Romanos, persistiu, segundo Pocock (2013), por mais de dois mil anos ao longo da história, produzindo reflexos até a atualidade. Há, a partir da cidadania clássica de Aristóteles, a separação entre o público e o privado, entre a polis e a oikos. O âmbito privado era destinado ao lar, ao mundo das coisas, as mulheres e escravos. Eram as mulheres que regiam e organizavam o trabalho do lar e dos escravos (ARISTÓTELES, 2009).

A cidadania era restrita a um certo número de indivíduos homens e adultos. Somente eles poderiam ser considerados cidadãos, com a capacidade de exercer a sua humanidade de forma plena. Eles participavam da política governando e sendo governados. Para isso, precisavam emancipar-se do lar, do mundo das coisas, para se dedicar à polis. Dessa forma, as mulheres eram excluídas da polis sob o argumento de estarem envolvidas demais no mundo das coisas. A oikos era o instrumento pelo qual se manejavam recursos para que a polis funcionasse de maneira correta, pois a política era um bem em si mesmo. Por isso, a mulher, no âmbito privado, por meio de seu trabalho e do trabalho dos escravos, acabava por fornecer subsídios para que o homem realmente se emancipasse da vida privada, para se dedicar com exclusividade para a vida pública (POCOCK, 2013).

Há uma constante dualidade entre o público e o privado que produzem reflexos para diversos âmbitos das vidas dos homens e das mulheres. Compreender como se desenhou essa fronteira no pensamento e nas normas políticas permite expor o seu caráter histórico e revelar suas implicações diferenciadas para mulheres e homens (BIROLI; MIGUEL, 2014).

Essa dualidade surgiu, como demonstrado no primeiro tópico, a partir de uma compreensão restrita da política, que, em nome da universalidade e impessoalidade da esfera pública, define uma série de atos e experiências que não pertencem ao âmbito político, mas ao âmbito privado. Segundo Flávia Biroli (2014), estabelecer fronteiras entre o público e o privado 
acaba por ser uma forma de isolar a política das relações de poder na vida cotidiana, negando ou desinflando o caráter político e conflitivo das relações de trabalho e relações familiares.

$\mathrm{Na}$ atualidade, a esfera pública seria espaço para a universalidade, razão e impessoalidade. Não é espaço para emoções e sentimentos. Já a esfera privada, seria espaço das relações envolvendo aspectos pessoais e íntimos. Na esfera pública os indivíduos são definidos como manifestações da humanidade ou de cidadania comum a todos. Na esfera privada, os indivíduos se apresentam em suas individualidades concretas e particulares.

A partir dessa divisão clássica entre os espaços, surge a criação de estereótipos de gênero, promovendo consequências negativas até os dias de hoje para as mulheres. Naturalmente, desde o período clássico, atribui-se papéis a elas, como a dedicação prioritária ao âmbito privado, à vida doméstica e aos familiares, colaborando para que a domesticidade feminina fosse vista como algo natural e distintivo, bem como um valor. Aos homens, ainda são atribuídos papéis relacionados à vida pública. A vinculação da mulher ao espaço privado acaba por provocar consequências que vão muito além desse espaço, provocando reflexos para o âmbito público.

Uma das consequências proveniente da atribuição do âmbito privado para as mulheres personifica-se na divisão sexual do trabalho, promovendo sua baixa participação na política formal, como evidenciam os dados dos cargos eletivos apresentados nesse artigo. A posição das mulheres nas relações de trabalho está no cerne das formas de exploração que caracterizam a dominação de gênero ou a própria presença do patriarcado. Nesta seara, afirma-se que a distinção entre trabalho remunerado e não remunerado é um ponto central dentro da separação entre espaços de poder.

Por serem naturais do âmbito privado desde a era clássica, o trabalho que as mulheres naturalmente exercem é sem remuneração, como aquele que está implicado na criação com os filhos, no cuidado de idosos, na realização de atividades domésticas, concedendo total abertura para que os homens se engajem em trabalhos remunerados e políticos. Segundo Flávia Biroli (2018) "são elas apenas que fornecem esse tipo de trabalho gratuitamente, e essa gratuidade se define numa relação: o casamento. É nele que o trabalho gratuito das mulheres pode ser caracterizado como não produtivo" (BIROLI, 2018, p. 28).

Ainda hoje, as mulheres sofrem pressões de toda a sociedade. Essas pressões estão relacionadas ao casamento e ao lar, pois, naturalmente, a mulher já nasce com um lugar prédefinido na sociedade: para ser feliz, precisará se casar com um homem. O destino que a 
sociedade propõe, tradicionalmente à mulher é o casamento. Segundo Simone de Beauvoir (2016), as mulheres são, ainda hoje, casadas, ou foram, ou se preparam para sê-lo, ou sofrem por não sê-lo.

A estrutura do casamento tradicional impõe a divisão de tarefas remuneradas e não remuneradas. O marido realiza grande parte da manutenção financeira do lar, realizando o sustento da família. Felizmente, as mulheres modernas têm entrado cada vez mais ao mercado de trabalho remunerado e, por isso, trabalham de forma remunerada também. Entretanto, segundo Carole Pateman (1999), o salário recebido pelo marido é o verdadeiro "ganha pão", já que promoverá o sustento da família. O salário recebido pela esposa, mesmo que seja igual ao salário do marido, nas famílias tradicionais, servirá apenas para pagar os seus luxos e de seus filhos (PATEMAN, 1999).

Além de trabalhar de forma remunerada no mercado de trabalho, a mulher ainda tem de arcar com as atividades domésticas do lar, por lhe serem naturalmente impostas. O trabalho remunerado não a exime de realizar as tarefas domésticas do lar. A sociedade e, consequentemente o casamento, tornam a mulher dona de um lar. Ela é a principal responsável pela sua casa, pela alimentação, pela limpeza, pelo cuidado com as roupas e, principalmente pelos filhos (BEAUVOIR, 2016). Por ser a principal responsável pelo lar e ainda trabalhar de forma remunerada no mercado de trabalho, as mulheres acabam por exercer duplas ou triplas jornadas de trabalho, já que ao voltarem do trabalho, têm de arcar, na maioria das vezes, exclusivamente, com o trabalho doméstico. Pesquisas realizadas por Natalie Itaboraí demonstram que as mulheres realizam muito mais tempo de atividades domésticas se comparada aos homens e o número de horas trabalhadas eleva-se ainda mais se a mulher for casada e se tiver filhos (ITABORAÍ, 2017).

Ainda tratando sobre os efeitos da destinação do âmbito privado para as mulheres, importante ressaltar que a diferenciação de gênero se faz presente entre o rendimento mensal dos homens e mulheres. Segundo Flávia Biroli, apesar de possuírem mais tempo de educação formal e de já terem ingressado no mercado de trabalho, a diferença entre o rendimento médio das mulheres e dos homens permanece em torno de $25 \%$, demonstrando que a profissionalização não garantiu acesso igualitário às diferentes ocupações (BIROLI, 2018, p. 21).

Ao terem que arcar com duplas jornadas de trabalho, desigualdades salariais, trabalhando de forma remunerada e arcando, quase que com exclusividade, com as atividades 
domésticas, as mulheres arcam com rotinas estressantes, proporcionando menos tempo e estruturas para realizar atividades que estejam fora do seu âmbito privado. Por tentarem realizar a conciliação entre ambas as atividades, a rotina de trabalho das mulheres fica muito superior que a rotina dos homens. E, por sua vez, acabam possuindo bem menos tempo para exercer suas atividades que não envolvam âmbito privado, como a participação política. A participação política exige que a mulher se envolva na rotina política. A mulher que concilia o trabalho remunerado com os afazeres domésticos sozinha, não possui estruturas e apoio em seu lar para que proporcione suporte na participação política. Ao tentar conciliar tantas atividades em sua rotina diária, ela perde seu tempo, o que acaba por provocar que a participação política fique para último plano. Quanto mais a mulher se envolve em sua vida privada, menos tempo ela terá para se engajar em sua vida pública.

Outro fator decorrente do conceito de cidadania clássica e da imputação do âmbito privado à mulher e que influencia drasticamente a participação das mulheres na política está relacionado com a renda. Como já mencionado, o rendimento médio entre homens e mulheres chegam em torno de $25 \%$. Mesmo com a educação que recebem ao longo de suas vidas, sofrem para adentrar no mercado de trabalho. Essa dificuldade de inserção no mercado de trabalho decorre, principalmente, em razão da discriminação entre os gêneros, que é muito mais sentida pelas mulheres que possuem filhos pequenos. As atividades domésticas que são imputadas a elas, impedem que as mesmas realizem trabalhos remunerados de forma integral na sociedade. Sem renda e tempo suficiente, surgem obstáculos para a inserção das mulheres na política, já que não terão condições para organizar o seu lar e colocar cuidadoras para seus filhos.

A consequente falta de tempo e renda, impedem também que a mulher construa suas redes de contato para ingressar na política. Pois, como veremos, para que a mulher alcance lugares de poder dentro do sistema político, faz-se necessário que essa construa sua rede de contato. Esta por sua vez, ampliaria "as possibilidades de construção de uma carreira política e mesmo de acesso a movimentos e espaços de organização coletiva” (BIROLI, 2018, p. 48).

Além das próprias consequências produzidas pela separação entre o público e o privado, importante ressaltar que o conceito clássico de cidadania foi criado naturalmente por homens, não sendo o âmbito político, portanto, um espaço para as mulheres propriamente. Pierre Bourdieu (2011) caracteriza o âmbito público, a política, como um campo político. Por campo político, entende-se ser um microcosmo, isto é, um pequeno mundo social relativamente autônomo no interior do grande mundo social. Nesse mundo se encontrará um grande número 
de propriedades, relações, ações e processos que se encontram no mundo global, mas esses processos, esses fenômenos se revestem de uma forma particular (BOURDIEU, 2011). Por ser autônomo, possui a sua própria lei, seu próprio nomos, que em si próprio, possuem o princípio e a sua própria regra de funcionamento. Possuem critérios de avaliação que não são válidos no microcosmo vizinho. "Um universo que obedece às suas próprias leis, que são diferentes das leis do mundo social ordinário" (BOURDIEU, 2011, p. 195). Quem entrar para a política deverá operar uma transformação, cumprir as regras do jogo político.

Quanto mais o campo político se torna autônomo, mais fechado ele se torna. Por possuir as suas próprias regras de funcionamento, também possui suas próprias regras de acesso, pois existem condições sociais de acesso à política. Desde a época clássica, o campo político é um espaço criado pelos homens e para os homens, constituindo-se num espaço verdadeiramente masculino. Dessa forma, verifica-se que o acesso das mulheres a esse campo se torna prejudicado, já que são impostos obstáculos para a sua participação, pois "no estado atual da divisão do trabalho entre os sexos as mulheres têm propensão muito menor do que os homens a responder às questões políticas” (BOURDIEU, 2011, p. 196).

Como um dos reflexos do conceito de cidadania clássica até a atualidade, verifica-se uma das condições sociais de possibilidade de acesso a esse microcosmo, como, por exemplo, o tempo livre. A emancipação das relações produtivas e a exclusividade para a política se constitui como um dos fatores de acesso ao campo político.

O sistema político é predominantemente e historicamente masculino. Suas estruturas de poder e sua hierarquização são originalmente androcêntricas. Neste sentido, o campo político trabalha contra as mulheres e em favor dos homens, impondo à elas obstáculos que impedem o seu acesso em âmbito político e, quando estas conseguem finalmente adentrar no campo, impondo barreiras para que não consigam chegar a posições de influência e poder, mesmo depois de terem sido eleitas mediante processo democrático (MIGUEL; BIROLI, 2014).

O tempo livre e total disposição para a política era uma das condições para se exercer a cidadania em seu conceito clássico (ARISTÓTELES, 2009). Entretanto, verifica-se ainda, na atualidade, o tempo livre como um dos requisitos necessários para acessar o jogo político. Para acessar ao campo político, o indivíduo precisa se emancipar de todas as suas relações produtivas e não produtivas a fim de que se dedique, exclusivamente, para a política.

A partir da ideia de imposição naturalizada de certas tarefas às mulheres, como as tarefas domésticas, o cuidado com os filhos, com o lar e, atualmente, com o trabalho, a mulher 
não possui tempo disponível para se envolver em outras relações sociais. Ao contrário, se houver a emancipação de suas tarefas "naturais", ela será excluída e julgada pela sociedade. Por não ter disponibilidade para se envolver em outras relações, ela permanece em seu espaço privado, exercendo suas atividades naturais, e concede abertura e estrutura social para que o homem se emancipe de seu espaço privado. Pode-se afirmar que esta é uma das consequências diretas do conceito de cidadania clássica, pois é ele quem se emancipa até hoje das relações sociais privadas para se dedicar, de forma exclusiva, as relações públicas.

Verifica-se, até hoje, as consequências produzidas pela cidadania clássica na participação das mulheres na política. Ainda há a separação entre o público e o privado, impondo lugares estereotipados para os gêneros. O espaço público foi criado e é destinado, naturalmente, aos homens. O espaço privado é destinado para as mulheres. São elas que permanecem no âmbito privado e concedem abertura para eles participarem no âmbito público. Essa separação, proveniente de um conceito clássico de cidadania, imputando papéis estereotipados a ambos os gêneros, acaba por provocar inúmeras consequências como as desigualdades de renda, de atividades entre homens e mulheres, as duplas ou triplas jornadas de trabalho, bem como a falta de tempo e de condições sociais e financeiras para que a mulher adentre no mundo político. Esses fatores, unidos, promovidos pelo conceito clássico de cidadania e, consequentemente, pela separação entre o público e o privado, acabam por promover obstáculos e a diminuição da participação feminina na política.

Nessa seara, a preservação da esfera privada em relação a esfera pública, significa a preservação das relações de autoridade que limitam a autonomia das mulheres. A garantia da separação entre o espaço público e privado acaba por ofuscar as vinculações entre os papéis e as posições de poder na esfera privada e na pública, pois não há como haver uma separação e uma destinação de espaço, ambos estão totalmente interligados entre si.

Quando se tem como objetivo a construção de uma sociedade democrática, é impossível descolar a esfera pública da privada, o espaço político da casa, a polis da oikos, a esfera política da vida social. Para haver uma maior igualdade entre os gêneros, é necessário, portanto, abandonar a visão de que a esfera privada e a esfera pública correspondem a "lugares" e "tempos" distintos na vida dos indivíduos. É necessário tratar ambos os espaços como um complexo diferenciado de relações, de práticas e de direitos, que estão permanentemente interligados, uma vez que os efeitos das relações de poder e dos direitos garantidos em uma esfera são sentidos na outra (MIGUEL; BIROLI, 2018). 


\section{6- CONSIDERAÇÕES FINAIS}

O texto buscou analisar as consequências produzidas pelo conceito de cidadania clássica na participação das mulheres na política atual brasileira. $\mathrm{O}$ estudo mostra que a separação entre o âmbito público e privado, entre a polis e a oikos, e o conceito clássico de cidadania persistiu, ao longo da história, por mais de dois mil anos e produz impactos até os dias de hoje. Quando se observa a participação das mulheres na política formal (cargos eletivos, por exemplo) e da imputação de espaços e papéis estereotipados aos gêneros, os dados revelam alguns desses impactos: as mulheres se fazem bem menos presentes no mundo político, preenchendo apenas 21,3\% das cadeiras parlamentares nacionais (MIGUEL, 2014), evidenciando uma das consequências que ainda são produzidas pelas noções trazidas nos conceitos tratados.

Existe uma estereotipização de gênero decorrente do conceito clássico de cidadania, o qual realiza uma rigorosa separação entre os âmbitos público, polis, e privado, oikos. O espaço privado era concedido às mulheres, às coisas e aos escravos. Eram elas que regiam e organizavam o lar. Os homens eram destinados à polis. Eram seres kata phusin zoon politikon, indivíduos que, por sua própria natureza, tendem a viver em política. Por terem a capacidade de governar e serem governados, apenas eles poderiam exercer a sua humanidade de forma plena.

A cidadania clássica era restritiva, isto é, destinada a apenas alguns indivíduos da sociedade: indivíduos adultos do sexo masculino. Apenas eles poderiam ser considerados cidadãos e poderiam adentrar no mundo político. Entretanto, para isso, deveriam se emancipar da oikos, do mundo das coisas, das mulheres e dos escravos. As mulheres não eram consideradas cidadãs, pois como pertenciam à oikos, estavam envolvidas demais no mundo das coisas para se envolverem no espaço público.

O conceito clássico de cidadania e a consequente separação entre os âmbitos público e privado permaneceram durante mais de dois mil anos ao longo da história e produzem efeitos até a atualidade. Esses efeitos podem ser verificados na atribuição de papéis e lugares estereotipados para os gêneros e a consequente baixa participação das mulheres na política.

Mesmo com as evoluções conquistadas pelas mulheres, como o sufrágio universal e igualdade formal entre os gêneros, ainda há a baixa participação das mulheres na política brasileira (formal), se comparada aos homens. Segundo o IBGE (2018), em nível mundial, dentre as 190 nações pesquisadas, o Brasil ocupa $152^{\mathrm{a}}$ posição no ranking mundial de 
participação das mulheres na política. Tais dados são contraditórios com o nível de formação educacional que essas mulheres possuem, bem como com composição do eleitorado brasileiro, formado em sua maioria por mulheres e mostram que o país ainda está distante de alcançar o ODS 5, compromisso para o país alcançar a igualdade de gênero e empoderar todas as mulheres e meninas.

O conceito clássico de cidadania e a separação entre os âmbitos público e privado acabam por promover a atribuição de papéis estereotipados para ambos os gêneros. A atribuição de papéis estereotipados para os gêneros, provoca que as mulheres estejam dedicadas ao âmbito privado de suas vidas e, quanto mais envolvidas no espaço privado, menores serão as chances de se envolverem no espaço público. Há, naturalmente, a imposição do espaço privado para as mulheres e para os homens o espaço público. São eles quem devem, naturalmente, participar ativamente da política.

A imposição do âmbito privado para as mulheres acaba por imputar diversas consequências, que unidas, promoverão obstáculos na inserção das mulheres no espaço público. A atribuição e naturalização das atividades domésticas, das desigualdades salariais, do trabalho remunerado e, da consequente dupla jornada de trabalho acabam por promover rotinas estressantes para as mulheres, não concedendo estrutura, suporte e tempo para que busquem se envolver no âmbito político. Há, na sociedade, a verdadeira naturalização de que o espaço privado é um lugar natural e exclusivo de mulheres. Por estarem presas a esse âmbito, não conseguem se emancipar e participar, de forma ativa, do âmbito político, ocasionando, de forma direta, a baixa participação feminina na política.

Além da própria estereotipização dos espaços, atribuindo a mulher o espaço privado, a política é naturalmente um campo ou um jogo político, segundo Bourdieu (2011). Possuem leis e estruturas próprias que deverão ser seguidas por quem deseja ingressar nela. É um campo político criado naturalmente por homens e para os homens. Não é um espaço destinado às mulheres. Por possuir suas leis próprias, há normas de acesso que obstaculizam a inserção das mulheres na política, como a necessidade de tempo livre para exercer a sua cidadania, longe de atividades não produtivas, mas principalmente, das produtivas. Pois como há a naturalização do espaço privado e de atividades domésticas para as mulheres, bem como a inserção no mercado de trabalho, é quase impossível a mulher conseguir se emancipar totalmente de suas atividades "naturais" que lhes são impostas, pois se assim fizesse, seria julgada e excluída pela sociedade, já que o seu espaço natural é o seu lar privado, a oikos. 
Dessa forma, verifica-se a presença das consequências produzidas pela cidadania clássica nos dias de hoje. Essas consequências personificam-se com a imposição do âmbito privado às mulheres e do âmbito público aos homens, promovendo estereótipos de gênero e obstáculos para a participação e inserção das mulheres na política, desencadeando a sua considerável baixa participação na vida pública.

Entretanto, para haver uma maior igualdade entre os gêneros, uma maior efetivação da cidadania e para a construção de uma sociedade mais democrática, é impossível separar o espaço privado do âmbito público. É necessário abandonar o conceito clássico de cidadania, no que diz respeito a separação da polis e da oikos, no sentido de que correspondam a lugares e tempos distintos na vida do indivíduo, para tratar ambos os âmbitos como um complexo diferenciado de relações, práticas e de direitos, que estão permanentemente imbricados, uma vez que os efeitos dos arranjos do espaço privado são sentidos no espaço público e vice-versa.

\section{REFERÊNCIAS}

ARISTÓTELES. A Política. Tradução: Nestor Silveira Chaves. $2^{\text {a }}$ ed. São Paulo: Edipro, 2009.

BEAUVOIR, Simone de. O Segundo Sexo: a experiência vivida. Vol. 2.3 ed. Rio de Janeiro: Nova Fronteira, 2016

BIROLI, Flávia. Divisão Sexual do Trabalho e Democracia. Rio de Janeiro: Revista de Ciências Sociais, vol. 59, $\mathrm{n}^{\mathrm{o}}$ 3, 2016. Disponível em: < http://dx.doi.org/10.1590/00115258201690>. Acesso em: 15 de dezembro de 2018.

BIROLI, Flávia. Gênero e Desigualdades: os limites da democracia no Brasil. São Paulo: Boitempo, 2018.

BOURDIEU, Pierre. "La Représentation Politique. Éléments pour une théorie du champ politique", Actes de la recherche en Sciences Sociales, n. 36-7, 1981, p. 3-24.

BORDIEU, Pierre. O Campo Político. Brasília: Revista Brasileira de Ciência Política, $\mathrm{n}^{\circ} 05$. 2011. Disponível em: http://www.scielo.br/scielo.php?script=sci_arttext\&pid=S010333522011000100008. Acesso em: 13 Dez. 2018.

BRASIL, CÂMARA DOS DEPUTADOS. Estudo analisa nova composição da Câmara por gênero e raça. 2014. Disponível em: http://www2.camara.leg.br/camaranoticias/radio/materias/COM-A-PALAVRA/475678ESTUDO-ANALISA-NOVA-COMPOSICAO-DA-CAMARA-POR-GENERO-ERACA.html>. Acesso em: 18 Dez. 2018. 
BRASIL. IBGE. Distribuição da População por Sexo. 2018 Disponível em: https://brasilemsintese.ibge.gov.br/populacao/distribuicao-da-populacao-por-sexo.html>.

Acesso em: 08 dez. 2018.

BRASIL. IBGE. Estatísticas de Gênero- indicadores socais das mulheres no Brasil. 2018. Disponível em: https://biblioteca.ibge.gov.br/visualizacao/livros/liv101551_informativo.pdf>. Acesso em: 23 dez. 2018.

BRASIL. IBGE. População do Brasil. 2008. Disponível em: https://www.ibge.gov.br/apps/populacao/projecao/. Acesso em: 20 de dezembro de 2018.

BRASIL. IBGE. Tarefas Domésticas Impõe Cargas de Trabalhos Maiores para as Mulheres. 2017. Disponível em:< https://agenciadenoticias.ibge.gov.br/agencia-noticias/2012agencia-de-noticias/noticias/18568-tarefas-domesticas-impoem-carga-de-trabalho-maior-paramulheres.html>. Acesso em: 06 dez. 2018.

BRASIL. Tribunal Superior Eleitoral. Estatísticas Eleitorais de 2010- Resultados. 2010. Disponível http://divulgacandcontas.tse.jus.br/divulga/\#/municipios/2010/14417/PA/candidatos. Acesso em: 08 dez. 2018.

BRASIL. Tribunal Superior Eleitoral. Estatísticas Eleitorais de 2012- Resultados. 2012. Disponível em:< http://divulgacandcontas.tse.jus.br/divulga/\#/2012>. Acesso em: 08 dez. 2018.

BRASIL. Tribunal Superior Eleitoral. Estatísticas Eleitorais de 2014- Resultados. 2014. Disponível http://divulgacandcontas.tse.jus.br/divulga/\#/municipios/2014/680/PA/cargos>. Acesso em: 08 dez. 2018.

BRASIL. Tribunal Superior Eleitoral. Estatísticas Eleitorais de 2016- Resultados. 2016. Disponível em: <http://www.tse.jus.br/eleicoes/estatisticas/eleicoes/eleicoesanteriores/estatisticas-eleitorais-2016/resultados>. Acesso em: 08 dez. 2018.

G1. Mulheres Passam o Dobro do Tempo que dos Homens com Tarefas Domésticas, aponta o IBGE. 2017. Disponível em: $<$ https://g1.globo.com/economia/noticia/mulherespassam-o-dobro-do-tempo-dos-homens-com-tarefas-domesticas-aponta-ibge.ghtml $>$. Acesso em: 19 dez. 2018.

ITABORAÍ, Nathalie Reis. Mudanças nas Famílias Brasileiras (1976-2012): uma perspectiva de classe e gênero. Rio de Janeiro: Garamond, 2017.

LIMA, Juliana Macedo de. Democracia no Brasil e participação das mulheres na política: algumas barreiras para o desenvolvimento democrático. Porto alegre: Universidade Federal do Rio Grande do Sul, 2015. Disponível em: < https://www.ufrgs.br/sicp/wpcontent/uploads/2015/09/10_DE-LIMA_Democracia-no-Brasil-eparticipac\%C2\%A6\% C2\%BAa\%C2\%A6\%C3\%A2o-das-mulheres-napoli\%C2\%A6\%C3\%BCtica.pdf>. Acesso em 10 jan. 2020. 
MIGUEL, Luis Felipe. Dominação e Resistência: desafios para uma política emancipatória. São Paulo: Boitempo, 2018.

MIGUEL, Luis Felipe; BIROLI, Flávia. Feminismo e Política: uma introdução. São Paulo: Boitempo, 2014.

PATEMAN, Carole. O Contrato Sexual. São Paulo: Paz e Terra, 1993.

PROGRAMA DAS NAÇÕES UNIDAS PARA O DESENVOLVIMENTO (PNUD). As perguntas mais frequentes sobre os Objetivos de Desenvolvimento Sustentável (ODS), 29 jun. 2016. Disponível em: https://www.undp.org/content/dam/brazil/docs/ODS/undp-br-odsFAQ.pdf. Acesso em: 18 jan. 2020.

PINHEIRO, Luana Simões. Mulheres e Trabalho: breve análise do período 2004-2014, Ipea, nota técnica n. 24, 2016, p. 3-28. Disponível em: < http://www.ipea.gov.br/portal/images/stories/PDFs/nota_tecnica/160309_nt_24_mulher_trabal ho_marco_2016.pdf>. Acesso em: 13 jan. 2020.

POCOCK, J.G.A. Cidadania, Historiografia e Res Publica: Contextos do pensamento político. Coimbra: Almedina, 2013. 